\title{
Rearing and foraging affects bumblebee (Bombus terrestris) gut microbiota
}

Article

Accepted Version

Newbold, L. K., Oliver, A. E., Cuthbertson, L., Walkington, S. E., Gweon, H. S., Heard, M. S. and van der Gast, C. J. (2015) Rearing and foraging affects bumblebee (Bombus terrestris) gut microbiota. Environmental Microbiology Reports, 7 (4). pp. 634-641. ISSN 1758-2229 doi: https://doi.org/10.1111/17582229.12299 Available at https://centaur.reading.ac.uk/75779/

It is advisable to refer to the publisher's version if you intend to cite from the work. See Guidance on citing.

To link to this article DOI: http://dx.doi.org/10.1111/1758-2229.12299

Publisher: Wiley-Blackwell

All outputs in CentAUR are protected by Intellectual Property Rights law, including copyright law. Copyright and IPR is retained by the creators or other copyright holders. Terms and conditions for use of this material are defined in the End User Agreement.

\section{www.reading.ac.uk/centaur}

\section{CentAUR}

Central Archive at the University of Reading 
Reading's research outputs online 
1 Rearing and foraging affects bumblebee (Bombus terrestris) gut microbiota

2

3 Lindsay K. Newbold ${ }^{\dagger}$, Anna E. Oliver ${ }^{\dagger}$, Leah Cuthbertson, Sarah E. Walkington, Hyun S. Gweon,

4 Matthew S. Heard*, Christopher J. van der Gast*

5

6 NERC Centre for Ecology \& Hydrology, Wallingford, OX10 8BB, UK

7

8

* Correspondence: C.J. van der Gast and M.S. Heard, NERC Centre for Ecology \& Hydrology,

9 Maclean Building, Benson Lane, Crowmarsh Gifford, Wallingford, OX10 8BB, UK. E-mail:

10 cjvdg@ceh.ac.uk and mshe@ceh.ac.uk

11

12

† Contributed equally to this work

13

14 Running title: Ecological effects on bumblebee gut microbiota

15

16 Keywords: Bombus terrestris / pollinators / gut microbiome / commonness and rarity / bumblebees /

17 bacterial communities

18

19 Data deposition: The sequence data reported in this paper have been deposited in the European

20 Nucleotide Archive under study accession number ERP007145, and sample accession number

$21 \quad$ ERS557783.

22 
Bumblebees are ecologically and economically important as pollinators of crop and wild plants, especially in temperate systems. Species, such as the buff-tailed bumblebee (Bombus terrestris), are reared commercially to pollinate high value crops. Their highly specific gut microbiota, characterised by low diversity, may affect nutrition and immunity and are likely to be important for fitness and colony health. However, little is known about how environmental factors affect bacterial community structure. We analyzed the gut microbiota from three groups of worker bumblebees (B. terrestris) from distinct colonies that varied in rearing and foraging characteristics: commercially reared with restricted foraging (RR); commercially reared with outside foraging (RF); and wild-caught workers (W). Contrary to previous studies, which indicate that bacterial communities are highly conserved across workers, we found that RF individuals had an intermediate community structure compared to RR and W types. Further, this was shaped by differences in the abundances of common OTUs and the diversity of rare

35 OTUs present which we propose results from an increase in the variety of carbohydrates obtained through foraging.

37 


\section{Introduction}

Insects and other pollinators provide a vital ecosystem service to $87.5 \%$ of the world's plant species (Ollerton et al., 2011) and demand for pollination services in crops is high (estimated global value of $€ 153$ billion; Gallai et al., 2009). As a consequence, there is an increasing awareness of the ecological and economic importance of such organisms. However, whilst demand for pollination services continues to rapidly increase, there is growing evidence for declines in pollinator populations (Biesmeijer et al., 2006; vanEngelsdorp et al., 2008; Aizen and Harder, 2009; Potts et al., 2010a; Potts et al., 2010b). Declines are likely driven by multiple factors including disease, pesticide use, host plant loss and changes in land management (Cameron et al., 2011; Dicks et al., 2013; Scheper et al., 2014). A link between the reduction of plant pollination, and a drop in pollinator diversity and abundance is also well established (Memmott et al., 2004; Biesmeijer et al., 2006; Albrecht et al., 2012). An increasing human population will only intensify demands on wild and managed pollinator populations to meet future food security needs (Klein et al., 2007; Aizen et al., 2008).

In temperate systems, eusocial bumblebees (Bombus spp.) are important and prolific plant pollinators. Some species are commercially managed to pollinate high value glasshouse and fruit crops (Klein et al., 2007; Leonhardt and Blüthgen, 2012). This practice is increasingly common, with between 30,000-60,000 bumblebee colonies per year being imported into the UK alone (Lye et al., 2011). Ensuring the production of healthy bumblebee colonies will be vital to sustain the growing demand for their services (Pettis et al., 2012). There is therefore interest in how commercially reared bees may differ from wild types in terms of physiology, and how interactions between them may affect fitness (Otterstatter and Thomson, 2008).

The insect gut is known to harbour a microbial community which is thought to aid host fitness through enhanced nutrition, immunity and colony health (Dillon and Dillon, 2004; Warnecke et al., 2007; Cariveau et al., 2014; Pernice et al., 2014). Recent studies suggest the Bombus gut bacterial community is predominately comprised of members from: Orbaceae (Gammaproteobacteria), Lactobacillaceae (Firmicutes), Neisseriaceae (Betaproteobacteria), Acetobacteraceae (Alphaproteobacteria), Bacteroidetes and Actinobacteria (Koch and Schmid-Hempel, 2012; Koch et al., 2013; Kwong and Moran, 2013; Cariveau et al., 2014). While much of the evidence suggests that 
the gut microbiota of bumblebees are highly conserved and of relatively low diversity (Koch and Schmid-Hempel, 2011b; Martinson et al., 2011) it has been shown that detectable shifts in bumblebee gut bacterial diversity may occur in response to infection (Koch et al., 2012; Cariveau et al., 2014). How other environmental changes affect gut microbial community structure remains unexplored.

Here, we utilized $16 \mathrm{~S}$ rRNA gene targeted next generation sequencing techniques to analyze the gut microbiota from three groups of individual adult female bumblebees (Bombus terrestris) from distinct colonies that were: commercially reared with no outside (restricted) foraging $(R R, n=6)$, commercially reared but released for outside foraging $(\mathrm{RF}, n=10)$ and field-caught workers collected from Buckinghamshire and the Isle of Wight, UK (W, $n=7)$. Given the low diversity and highly specific microbiota reported previously, we adopted a null hypothesis that diversity and composition of $B$. $t$. audax host gut microbiota would not be influenced by rearing and foraging conditions. The current study aimed to establish whether gut microbiota responded to host foraging, i.e. does a commercially reared host, with controlled food resources (within colony standardised pollen and nectar solution) have a detectably different gut microbiota from that of wild populations.

84 
Bacterial diversity and composition from whole gut samples was assessed using 16S rRNA gene targeted high-throughput sequencing. From 23 bee gut samples, a total of 2,465,708 sequence reads (mean \pm SD per sample, 107204.7 \pm 59212.6 ) were included in the final analysis and 373 distinct operational taxonomic units (OTUs) identified. The average numbers of bacterial sequence reads per sample were similar among the three groups: commercially reared but restricted to colony (RR), $96,484 \pm 55,741(n=6)$; commercially reared but with outside foraging (RF), 100,533 $\pm 53,812(n=$ 10); and wild-caught workers (W), $125,924 \pm 64,867(n=7)$. The number of OTUs we identified is higher than that in studies applying traditional culture independent techniques - ranging from 9 to 146 sequenced OTUs (Koch and Schmid-Hempel, 2011b; Martinson et al., 2011).Thus, the increased sampling depth through the application of next generation sequencing (NGS) appears to have captured more of the inherent gut microbial diversity. When compared to other insects guts (e.g up to 726 OTUs were identified in the termite hind gut alone, Köhler et al., 2012), an overarching richness of 373 OTUs is relatively low, although comparable to that of the honey bee (Moran et al., 2012), suggesting that the bumblebee gut microbiome does indeed represent a low diversity, specialized

It is expected that a microbial metacommunity would display a positive relationship between frequency and abundance of individual taxa (OTUs) from within its constituent communities (van der Gast et al., 2011). Consistent with this prediction, the abundance of individual bacterial OTUs, across all samples (Figure 1a), was significantly correlated with the number of individual gut sample communities that they occupied. Separating component taxa within a host microbiota into common and rare groupings reveals important aspects of taxa-abundance distributions (van der Gast et al., 2011; van der Gast et al., 2014). Here, we partitioned the OTUs into 'common' (defined as those present in the upper quartile of sample occupancy with $>75 \%$ across all samples) and 'rare' groupings. The 28 common OTUs accounted for $97.4 \%$ of the total sequence abundance while the rare group comprised the majority of the diversity (345 'rare' OTUs). Similarly, Cariveau et al. (2014) determined that high abundance OTUs represented $98.9 \%$ of sequences from B. bimaculatus and $B$. impatiens gut microbiota samples. 
117 Mean OTU richness in the whole microbiota was significantly higher within the RF group (121.5 \pm

118 10.4, mean $\pm \mathrm{SD}$ ) when compared to the other samples (RR, $97.2 \pm 18.7$; and $\mathrm{W}, 83.0 \pm 2.1$; Figure

$1191 \mathrm{~b}$ and Table S1). The same significant pattern was reflected in the rare microbiota $(\mathrm{RR}, 71.2 \pm 18.1$;

$120 \mathrm{RF}, 96.8 \pm 9.8$; and $\mathrm{W}, 57.4 \pm 2.0$ ), but not in the common microbiota which did not significantly differ

121 between groups (RR, $26.0 \pm 1.2 ; \mathrm{RF}, 24.7 \pm 1.11$; and $\mathrm{W}, 25.6 \pm 0.8$; Figure $1 \mathrm{~b}$ and Table $\mathrm{S} 1)$. We

122 therefore assert that observed patterns in richness are driven by compositional changes in the rare

123 microbiota. This was confirmed by pair wise comparisons of turnover rates (number of taxa/OTUs

124 eliminated and replaced; Figure 1c), where whole microbiota turnover between groups followed that of

125 the rare microbiota comparisons. No turnover was observed between the common microbiota (Figure

126 1c), however the common microbiota did contribute most to patterns of whole microbiota composition

127 (Figure 1d). Bray-Curtis quantitative index similarity $\left(S_{B C}\right)$ revealed the whole microbiota to be highly

128 similar to the corresponding common microbiota (mean $S_{B C}=0.99 \pm 0.01, n=3$ pair wise

129 comparisons). Conversely, the rare microbiota was highly dissimilar between whole microbiota and

130 corresponding rare microbiota (mean $S_{\mathrm{BC}}=0.04 \pm 0.03$ ), and were divergent between rare microbiota

131 groups (mean $S_{B C}=0.23 \pm 0.15 ;$ Figure 1d).

132

133 Analysis of the uniqueness and sample group allocation of OTUs (Figure 2) demonstrated that, in

134 addition to the 28 common OTUs, a further 102 OTUs (taxa) were shared across all treatments.

135 These appear to be an integral part of the wild B. t. audax gut microbiota, and therefore likely to be

136 retained across generations. Interestingly, when looking at the allocation of rare OTUs the reared

137 foraging group had the highest number unique of OTUs (75) when compared to the other sample

138 group types $(R R=9, W=13)$. Further, none of the OTUs detected were shared solely between the

139 RR and W groups, suggesting that although gut microbiota from commercially reared populations are

140 distinct from wild populations, when allowed to forage a shift in microbiota from a commercially reared

141 to wild pattern occurs. As such the RF group would represent a population with microbiota in flux,

142 showing a pattern which shares both commercially reared and wild attributes. If this is the case it

143 would be interesting to consider whether the RF gut microbiota population would fully transition to a

144 wild type and how long such a transition would take. Analysis of similarity (ANOSIM) tests give further

145 weight to the patterns observed. While the microbiota (whole, common and rare) from RR and W 
samples were significantly divergent (Table 1), the RF microbiota shared attributes with both the RR and W groups' microbiota.

In order to determine which OTUs contributed most to the observed shift in community abundance and composition similarity percentage (SIMPER) analysis was performed (Table 2). Representative OTUs commonly found within insect and hymenopteran guts were prevalent within the bumblebees studied here - including members of the Neisseriaceae, Orbaceae, Enterobacteriaceae, Lactobacillaceae, Pseudomonadaceae and Bifidobacteriaceae (Kosako et al., 1984; Babendreier et al., 2007; Novakova et al., 2009; Killer et al., 2010; Wilkes et al., 2011; Koch et al., 2013; Duron, 2014; Engel et al., 2014; Killer et al., 2014b; Killer et al., 2014a). Two common microbiota group OTUs, identified as Snodgrassella alvi and Gilliamella apicola, contributed the most to the dissimilarity between groups. Both have previously been found to be dominant members within honeybees and other bumblebee species (Koch and Schmid-Hempel, 2011a; Kwong and Moran, 2013). S. alvi had a higher relative abundance in the RR samples (52.1\%) than both the RF $(29.5 \%)$ and W $(22.4 \%)$ samples. Conversely, G. apicola was more abundant in the wild samples $(30.9 \%)$ than the reared (RR $=22.9 \%$ and $\mathrm{RF}=17.9 \%)$.

162

Analysis of the genomes of these organisms has suggested that they perform complementary roles within the bee gut. Kwong et al. (2014b) suggest that G. apicola is a saccharolytic fermenter, possessing the genes for pathways associated with carbohydrate metabolism, whereas S.alvi shows no evidence of these, instead possessing pathways involved in the metabolism of carboxylates. It appears that increases in G. apicola mean relative abundance in the wild bees represents a biological response to increased foraging (i.e, a wide range of pollen and nectar types) which contrasts with commercially reared bees, fed upon a single nectar source and restricted (irradiated) pollen. This is further supported by the presence of other OTUs which exhibited increases in relative abundances related to foraging. The common OTU identified as Arsenophonus nasoniae demonstrated an

172 increase in abundance in favour of foraging ability $(R R=0.02 \%, R F=6.1 \%$, and $W=15.8 \%$, Table 2$)$. A genomic study based upon Arsenophonus nasoniae indicated that this species contains intact

174 pathways for carbohydrate metabolism (Darby et al., 2010). A common OTU identified as 
176 Fructobacillus is a group of fructophilic lactic acid bacteria that prefer fructose as a growth substrate 177 and inhabit fructose-rich habitats, including bumble (Koch and Schmid-Hempel, 2011b) and honey 178 bee guts (Endo and Salminen, 2013). Interestingly, there appeared to be role differences occurring within related taxa. Members of the Lactobacillus genus are able to metabolise multiple carbohydrate types (Killer et al., 2014a; Kwong et al., 2014a); here a common OTU identified as Lactobacillus kunkeei increased in relative abundance with the ability to forage, whereas another common and distinct Lactobacillus OTU decreased (Table 2). Overall, wild foraging represents an increase in the range and diversity of pollen/nectar sources and therefore the bacteria able to process these additional carbohydrate types.

Finally, canonical correspondence analysis revealed that variance in microbiota was explained by foraging, rearing and host weight (Table 3 and Figure S1). Undetermined variation could be explained by factors not measured here, for example infection with microbial parasites (e.g. Crithidia and Nosema) and colony age; both previously associated with differences in Bombus spp. gut communities (Koch et al., 2012; Cariveau et al., 2014).

191

In eusocial bees common bacteria are often considered to be synonymous with indigenous/core host gut microbes and are most likely acquired through vertical transmission or within colony interactions (Powell et al., 2014). In contrast, rare/non-core microbiota often contain members which are associated with non-host environments, and are most likely acquired though horizontal transmission (Cariveau et al., 2014). Within our study the rare bacteria shaped observed patterns in diversity. We suggest these detected changes are likely to be through low abundance organisms which have changed in response to host bees foraging on more diverse food resources, in addition to the horizontal acquisition of bacteria from the environment. In a recent study in honey bees it was found that the majority of transmission of gut bacteria was through within hive interactions, rather than environmental exposure (Powell et al., 2014). If this pattern holds true for bumblebees it would suggest that, although the environment does undoubtedly serve as an important and variable reservoir for bacterial immigration, the existing gut microbiota has the capacity to adapt to new foraging resources. 
206 Overall, we have shown that significant variation in microbiota can result from intraspecific differences

207 in bumblebee rearing and foraging. Given the vital ecosystem services bumblebees provide in

208 pollination of crop and native plants future work should focus on the temporal and functional

209 significance of these shifts in bacterial diversity and composition, and any subsequent effect upon

210 host health and fitness. 
212 Bumblebee samples

213 Commercially reared (Biobest N.V., Westerlo, Belgium) mature female worker individuals of Bombus

214 terrestris audax (Table S2) were collected after 26 days into the experiment from distinct colonies that 215 were restricted to colony ( $\mathrm{RR}, n=6$ ) or allowed to forage ( $\mathrm{RF}, n=10)$ in agricultural land near to the 216 NERC Centre for Ecology \& Hydrology, Wallingford, Oxfordshire, UK. Wild female worker individuals 217 (W, $n=7)$ were collected in July 2009 from within agricultural landscapes on the Isle of Wight, UK ( $n$ $=3$ ), and the Hillesden Estate, Buckinghamshire, UK $(n=4)$ as part of a previous study (Carvell et al., 2012). Molecular microsatellite analysis data were examined, generated from a previous study (Carvell et al., 2012), to minimise probability of processing collected individuals from the same colony. Members of the reared restricted (RR) group were reared within laboratory conditions with a diet consisting of 'Biogluc' (a 66\% commercial sugar solution) and fresh (frozen), gamma irradiated pollen, both supplied by Biobest N.V, Belgium. Members of the reared foraged group (RF) were treated identically to the lab reared group until introduction to the wild. At this point - in order to encourage foraging from the local agricultural landscape - no additional nutritional substitute was provided. RR and RF individuals were sampled during July and August 2013.

DNA extraction and sequencing

Whole guts from individual specimens (frozen at $-80^{\circ} \mathrm{C}$ within 2 hours of collection) which had been commercially reared or captured in the wild, were used to extract microbiome DNA using the PowerSoil@-htp 96 Well Soil DNA Isolation Kit (Mobio Laboratories Inc., Carlsbad, CA), under the manufacturers recommended protocol. In addition, PCR negative controls consisting of extraction and PCR blanks were also processed and likely kit contaminants removed from analysis (Salter et al., 2014). Approximately $20-30 \mathrm{ng}$ of template DNA was amplified using Q5® high-fidelity DNA polymerase (New England Biolabs, Hitchin, UK) each with a unique golay barcoded primer. After an initial denaturation step at $98^{\circ} \mathrm{C}$ for 2 min, individual PCR reactions employed 25 cycles of an initial $30 \mathrm{sec}, 98^{\circ} \mathrm{C}$ denaturation step, followed by annealing phase for $30 \mathrm{sec}$ at $53^{\circ} \mathrm{C}$, and final extension step lasting 90 secs at $72{ }^{\circ} \mathrm{C}$. All reactions employed a final extension step of 5 min at $72^{\circ} \mathrm{C}$. Primers based upon the universal primers 27F (5'- CCATCTCATCCCTGCGTGTCTCCGACTCAG) and 338R 
et al., 2012) and spacer sequences (Table S2). An amplicon library consisting of $\sim 400$ bp amplicons spanning the V1-V2 hypervariable regions of the 16S rRNA gene was generated from gel purified pooled products of 4 replicate PCR reactions, per sample. Quantification was performed on an Agilent 2200 TapeStation system and an equimolar mix of PCR products was prepared and diluted to 20pM in $\mathrm{dH}_{2} \mathrm{O}$. This library was sequenced using an Ion Torrent Personal Genome Machine (Life Technologies, Paisley, UK) with a 316 chip.

\section{Sequence analysis}

The Mothur sequencing analysis platform was used to analyse the resulting data (Schloss et al., 2009; Schloss et al., 2011). Sequence quality checks included the removal of failed reads, low-quality ends, tags and primers. Further, sequences were aligned against the Mothur SILVA reference bacterial database and any unaligned sequences that included ambiguous base calls and/or homopolymers longer than 8 bases were also eliminated. Finally, chimeras were identified and discarded through Mothur using the UCHIME algorithm (Edgar et al., 2011). The resultant alignment was used to assemble operational taxonomic unit (OTU) clusters at $96 \%$ identity, through distance measures (Schloss and Handelsman, 2005, 2006). Taxonomic identity of these OTUs was assigned using the default settings with the mothur RDP reference database. As an additional measure the identity of reference sequences from key OTUs was corroborated using the NCBI's BLASTN program. OTUs identified in negative controls were removed from further analysis (Salter et al., 2014). The raw sequence data reported in this study have been deposited in the European Nucleotide Archive under study accession number ERP007145 and sample accession number ERS557783. The relevant barcode information for each sample is shown in Table $\mathbf{S} 2$.

\section{Statistical analysis}

Operational taxonomic units (OTUs) were partitioned into common and rare microbiota groups using a modification of the method previously described (van der Gast et al., 2011; van der Gast et al., 2014). Based on a significant positive distribution-abundance relationship, the persistent and abundant common OTUs were defined as those in more than $75 \%$ of all samples, while all other OTUs falling outside of the upper quartile were considered to be rare. Richness $\left(S^{\star}\right)$ was used as previously described (Rogers et al., 2013). It is known that pair wise comparisons will be affected by large 
271

272

273

274

275

276

differences in sample size (Gihring et al., 2012). Therefore, $S^{*}$ was calculated with a uniform resample size (to match the smallest sequence size in each microbiota group [whole, common, and rare]) following 1000 iterations in each instance and performed in R version 3.1.1 (Oksanen et al., 2013; The R Development Core Team, 2013)

Taxa turnover between consecutive samples was measured using the method described by Brown and Kodric-Brown (1977). Turnover was defined as: $t=b+c / S 1+S 2$. Where $b=$ the number of OTUs present only in the first sample; $c=$ the number of OTUs present only in the second sample; $S 1$ $=$ the total number of OTUs in the first sample; and $S 2$ the total number of OTUs in the second sample (Brown and Kodric-Brown, 1977). Two-sample $t$-tests, regression analysis, coefficients of determination $\left(r^{2}\right)$, residuals and significance $(P)$ were calculated using Minitab software (version 16, Minitab, University Park, PA, UK). The Bray-Curtis quantitative index of similarity and subsequent average linkage clustering of community profiles was performed using PAST (Paleontological Statistics, version 3.01) program, available from the University of Oslo (http://folk.uio.no/ohammer/past). Analysis of similarity (ANOSIM) and similarity of percentages analysis (SIMPER) were performed using the PAST (version 3.01). The Bray-Curtis quantitative index of similarity was used as the underpinning community similarity measure for both ANOSIM and SIMPER analyses. Canonical correspondence analysis (CCA) was used to relate the variability in the distribution of microbiota between groups to environmental factors. Environmental variables that significantly explained variation in the gut microbiota were determined with forward selection (999 Monte Carlo permutations; $P<0.05)$ and used in CCA. CCA analyses were preformed in PAST (version 3.01) as previously described (Hazard et al., 2013).

\section{Acknowledgments}

This work was supported by the NERC Centre for Ecology \& Hydrology (CEH). We thank Sarah Hulmes, Lucy Hulmes, Jo Savage, and Claire Carvell (all CEH) for field sample collections. 
Aizen, M.A., and Harder, L.D. (2009) The Global Stock of Domesticated Honey Bees Is Growing

Aizen, M.A., Garibaldi, L.A., Cunningham, S.A., and Klein, A.M. (2008) Long-Term Global Trends in Crop Yield and Production Reveal No Current Pollination Shortage but Increasing Pollinator Dependency. Curr Biol 18: 1572-1575.

Albrecht, M., Schmid, B., Hautier, Y., and Müller, C.B. (2012) Diverse pollinator communities enhance plant reproductive success. Proc $R$ Soc B 279: 4845-4852

Babendreier, D., Joller, D., Romeis, J., Bigler, F., and Widmer, F. (2007) Bacterial community structures in honeybee intestines and their response to two insecticidal proteins. FEMS Microbiol Ecol 59: $600-610$.

Biesmeijer, J.C., Roberts, S.P.M., Reemer, M., Ohlemüller, R., Edwards, M., Peeters, T. et al. (2006) Parallel Declines in Pollinators and Insect-Pollinated Plants in Britain and the Netherlands. Science 313: 351-354.

Brown, J.H., and Kodric-Brown, A. (1977) Turnover rates in insular biogeography: Effect of immigration and extinction. Ecology 58: 445-449.

Cameron, S.A., Lozier, J.D., Strange, J.P., Koch, J.B., Cordes, N., Solter, L.F., and Griswold, T.L. (2011) Patterns of widespread decline in North American bumble bees. P Natl Acad Sci USA 108: 662-667.

Cariveau, D.P., Elijah Powell, J., Koch, H., Winfree, R., and Moran, N.A. (2014) Variation in gut microbial communities and its association with pathogen infection in wild bumble bees (Bombus). ISME J 8: 2369-2379.

Carvell, C., Jordan, W.C., Bourke, A.F.G., Pickles, R., Redhead, J.W., and Heard, M.S. (2012) Molecular and spatial analyses reveal links between colony-specific foraging distance and landscapelevel resource availability in two bumblebee species. Oikos 121: 734-742.

Darby, A.C., Choi, J.H., Wilkes, T., Hughes, M.A., Werren, J.H., Hurst, G.D., and Colbourne, J.K. (2010) Characteristics of the genome of Arsenophonus nasoniae, son-killer bacterium of the wasp Nasonia. Insect Mol Biol 19 Suppl 1: 75-89.

Dicks, L.V., Abrahams, A., Atkinson, J., Biesmeijer, J., Bourn, N., Brown, C. et al. (2013) Identifying key knowledge needs for evidence-based conservation of wild insect pollinators: a collaborative cross-sectoral exercise. Insect Conserv Diver 6: 435-446.

Dillon, R.J., and Dillon, V.M. (2004) The Gut Bacteria of Insects: Nonpathogenic Interactions. Annual Review of Entomology 49: 71-92.

Duron, O. (2014) Arsenophonus insect symbionts are commonly infected with APSE, a bacteriophage involved in protective symbiosis. FEMS Microbiol Ecol 90: 184-194

Edgar, R.C., Haas, B.J., Clemente, J.C., Quince, C., and Knight, R. (2011) UCHIME improves sensitivity and speed of chimera detection. Bioinformatics 27: 2194-2200.

Endo, A., and Salminen, S. (2013) Honeybees and beehives are rich sources for fructophilic lactic acid bacteria. Syst Appl Microbio/ 36: 444-448.

Engel, P., Stepanauskas, R., and Moran, N.A. (2014) Hidden Diversity in Honey Bee Gut Symbionts Detected by Single-Cell Genomics. PLoS Genet 10: e1004596.

Gallai, N., Salles, J.-M., Settele, J., and Vaissière, B.E. (2009) Economic valuation of the vulnerability of world agriculture confronted with pollinator decline. Ecol Econ 68: 810-821. 
Gihring, T.M., Green, S.J., and Schadt, C.W. (2012) Massively parallel rRNA gene sequencing exacerbates the potential for biased community diversity comparisons due to variable library sizes. Environ Microbiol 14: 285-290.

Hazard, C., Gosling, P., van der Gast, C.J., Mitchell, D.T., Doohan, F.M., and Bending, G.D. (2013) The role of local environment and geographical distance in determining community composition of arbuscular mycorrhizal fungi at the landscape scale. ISME J 7: 498-508.

Killer, J., Votavová, A., Valterová, I., Vlková, E., Rada, V., and Hroncová, Z. (2014a) Lactobacillus bombi sp. nov., from the digestive tract of laboratory-reared bumblebee queens (Bombus terrestris). Int J Syst Evol Micr 64: 2611-2617.

Killer, J., Kopečný, J., Mrázek, J., Havlík, J., Koppová, I., Benada, O. et al. (2010) Bombiscardovia coagulans gen. nov., sp. nov., a new member of the family Bifidobacteriaceae isolated from the digestive tract of bumblebees. Syst Appl Microbiol 33: 359-366.

Killer, J., Švec, P., Sedláček, I., Černohlávková, J., Benada, O., Hroncová, Z. et al. (2014b) Vagococcus entomophilus sp. nov., from the digestive tract of a wasp (Vespula vulgaris). Int $J$ Syst Evol Micr 64: 731-737.

Klein, A.-M., Vaissière, B.E., Cane, J.H., Steffan-Dewenter, I., Cunningham, S.A., Kremen, C., and Tscharntke, T. (2007) Importance of pollinators in changing landscapes for world crops. Proc $R$ Soc $B$ 274: 303-313.

Koch, H., and Schmid-Hempel, P. (2011a) Socially transmitted gut microbiota protect bumble bees against an intestinal parasite. Proc Natl Acad Sci USA 108: 19288-19292.

Koch, H., and Schmid-Hempel, P. (2011b) Bacterial communities in central European bumblebees: low diversity and high specificity. Microbial Ecol 62: 121-133.

Koch, H., and Schmid-Hempel, P. (2012) Gut microbiota instead of host genotype drive the specificity in the interaction of a natural host-parasite system. Ecol Lett 15: 1095-1103.

Koch, H., Cisarovsky, G., and Schmid-Hempel, P. (2012) Ecological effects on gut bacterial communities in wild bumblebee colonies. J Anim Ecol 81: 1202-1210.

Koch, H., Abrol, D.P., Li, J., and Schmid-Hempel, P. (2013) Diversity and evolutionary patterns of bacterial gut associates of corbiculate bees. Mol Ecol 22: 2028-2044.

Köhler, T., Dietrich, C., Scheffrahn, R.H., and Brune, A. (2012) High-Resolution Analysis of Gut Environment and Bacterial Microbiota Reveals Functional Compartmentation of the Gut in WoodFeeding Higher Termites (Nasutitermes spp.). Appl Environ Microb 78: 4691-4701.

Kosako, Y., Sakazaki, R., and Yoshizaki, E. (1984) Yokenella regensburgei gen. nov., sp. nov.: a new genus and species in the family Enterobacteriaceae. Jpn J Med Sci Biol 37: 117-124.

Kwong, W.K., and Moran, N.A. (2013) Cultivation and characterization of the gut symbionts of honey bees and bumble bees: description of Snodgrassella alvi gen. nov., sp. nov., a member of the family Neisseriaceae of the Betaproteobacteria, and Gilliamella apicola gen. nov., sp. nov., a member of Orbaceae fam. nov., Orbales ord. nov., a sister taxon to the order 'Enterobacteriales' of the Gammaproteobacteria. Int J Syst Evol Microbiol 63: 2008-2018.

Kwong, W.K., Mancenido, A.L., and Moran, N.A. (2014a) Genome Sequences of Lactobacillus sp. Strains wkB8 and wkB10, Members of the Firm-5 Clade, from Honey Bee Guts. Genome Announc 2.

Kwong, W.K., Engel, P., Koch, H., and Moran, N.A. (2014b) Genomics and host specialization of honey bee and bumble bee gut symbionts. Proc Natl Acad Sci USA 111: 11509-11514. 
Leonhardt, S., and Blüthgen, N. (2012) The same, but different: pollen foraging in honeybee and bumblebee colonies. Apidologie 43: 449-464.

Lye, G.C., Jennings, S.N., Osborne, J.L., and Goulson, D. (2011) Impacts of the use of Nonnative Commercial Bumble Bees for Pollinator Supplementation in Raspberry. J Econ Entomol 104: 107114.

Martinson, V.G., Danforth, B.N., Minckley, R.L., Rueppell, O., Tingek, S., and Moran, N.A. (2011) A simple and distinctive microbiota associated with honey bees and bumble bees. Mol Ecol 20: 619628.

Memmott, J., Waser, N.M., and Price, M.V. (2004) Tolerance of pollination networks to species extinctions. Proc R Soc B 271: 2605-2611.

Moran, N.A., Hansen, A.K., Powell, J.E., and Sabree, Z.L. (2012) Distinctive Gut Microbiota of Honey Bees Assessed Using Deep Sampling from Individual Worker Bees. PLoS ONE 7: e36393.

Novakova, E., Hypsa, V., and Moran, N. (2009) Arsenophonus, an emerging clade of intracellular symbionts with a broad host distribution. BMC Microbio/ 9: 143.

Oksanen, J., Guillaume Blanchet, F., Kindt, R., Legendre, P., Minchin, P.R., O'Hara, R.B. et al. (2013) Package vegan: community ecology package. R package version 2.0-7. Vienna, Austria.: $\mathrm{R}$ Foundation for Statistical Computing.

Ollerton, J., Winfree, R., and Tarrant, S. (2011) How many flowering plants are pollinated by animals? Oikos 120: 321-326.

Otterstatter, M.C., and Thomson, J.D. (2008) Does Pathogen Spillover from Commercially Reared Bumble Bees Threaten Wild Pollinators? PLoS ONE 3: e2771.

Pettis, J.S., van Engelsdorp, D., Johnson, J., and Dively, G. (2012) Pesticide exposure in honey bees results in increased levels of the gut pathogen Nosema. Naturwissenschaften 99: 153-158.

Pernice, M., Simpson, S.J., and Ponton, F. (2014) Towards an integrated understanding of gut microbiota using insects as model systems. Journal of Insect Physiology 69: 12-18.

Potts, S.G., Biesmeijer, J.C., Kremen, C., Neumann, P., Schweiger, O., and Kunin, W.E. (2010a) Global pollinator declines: trends, impacts and drivers. Trends Ecol Evol 25: 345-353.

Potts, S.G., Roberts, S.P.M., Dean, R., Marris, G., Brown, M.A., Jones, R. et al. (2010b) Declines of managed honey bees and beekeepers in Europe. J Apicult Res 49: 15-22.

Powell, J.E., Martinson, V.G., Urban-Mead, K., and Moran, N.A. (2014) Routes of acquisition of the gut microbiota of Apis mellifera. Appl Environ Microbiol. Accepted manuscripted posted online sept 2014

Rogers, G.B., Cuthbertson, L., Hoffman, L.R., Wing, P.A.C., Pope, C., Hooftman, D.A.P. et al. (2013) Reducing bias in bacterial community analysis of lower respiratory infections. ISME J 7: 697-706.

Salter, S.J., Cox, M.J., Turek, E.M., Calus, S.T., Cookson, W.O., Moffatt, M.F. et al. (2014) Reagent and laboratory contamination can critically impact sequence-based microbiome analyses. BMC Biol 12: 87

Scheper, J., Reemer, M., van Kats, R., Ozinga, W.A., van der Linden, G.T.J., Schaminée, J.H.J. et al. (2014) Museum specimens reveal loss of pollen host plants as key factor driving wild bee decline in The Netherlands. Proc Natl Acad Sci USA 111: 17552-17557.

Schloss, P.D., and Handelsman, J. (2005) Introducing DOTUR, a Computer Program for Defining Operational Taxonomic Units and Estimating Species Richness. Appl Environ Microbiol 71: 15011506. 
Schloss, P.D., and Handelsman, J. (2006) Introducing SONS, a Tool for Operational Taxonomic UnitBased Comparisons of Microbial Community Memberships and Structures. Appl Environ Microbiol 72 : 6773-6779.

Schloss, P.D., Gevers, D., and Westcott, S.L. (2011) Reducing the effects of PCR amplification and sequencing artifacts on $16 \mathrm{~S}$ rRNA-based studies. PLOS ONE 6: e27310.

Schloss, P.D., Westcott, S.L., Ryabin, T., Hall, J.R., Hartmann, M., Hollister, E.B. et al. (2009) Introducing mothur: Open-Source, Platform-Independent, Community-Supported Software for Describing and Comparing Microbial Communities. Appl Environ Microbiol 75: 7537-7541.

The R Development Core Team (2013) R: a language and environment for statistical computing. Vienna, Austria: R Foundation for Statistical Computing.

van der Gast, C.J., Walker, A.W., Stressmann, F.A., Rogers, G.B., Scott, P., Daniels, T.W. et al. (2011) Partitioning core and satellite taxa from within cystic fibrosis lung bacterial communities. ISME J 5: 780-791.

van der Gast, C.J., Cuthbertson, L., Rogers, G.B., Pope, C., Marsh, R.L., Redding, G.J. et al. (2014) Three clinically distinct chronic pediatric airway infections share a common core microbiota. Ann Am Thorac Soc 11: 1039-1048.

vanEngelsdorp, D., Hayes, J., Jr., Underwood, R.M., and Pettis, J. (2008) A Survey of Honey Bee Colony Losses in the U.S., Fall 2007 to Spring 2008. PLoS ONE 3: e4071.

Warnecke, F., Luginbuhl, P., Ivanova, N., Ghassemian, M., Richardson, T.H., Stege, J.T. et al. (2007) Metagenomic and functional analysis of hindgut microbiota of a wood-feeding higher termite. Nature 450: $560-565$

Whiteley, A.S., Jenkins, S., Waite, I., Kresoje, N., Payne, H., Mullan, B. et al. (2012) Microbial 16S rRNA Ion Tag and community metagenome sequencing using the lon Torrent (PGM) Platform. $J$ Microbiol Method 91: 80-88.

Wilkes, T.E., Duron, O., Darby, A.C., Hypa, V., Nováková, E., and Hurst, G.D.D. (2011) The Genus Arsenophonus. In Manipulative Tenants: Bacteria Associated with Arthropods, Zchori-Fein, E., and Bourtzis, K. (eds). Danvers, M A: CRC Press, pp. 225-244. 


\section{$515 \quad$ Figure and Table legends}

516 Figure 1 Comparisons of community characteristics between bee groups. (a) Distribution and 517 abundance of OTUs from bee gut microbiota samples. Given is the number of samples for which 518 each bacterial taxon was observed to occupy, plotted against the mean abundance across all 519 samples $\left(n=23, r^{2}=0.68, F_{1,371}=787.6, P<0.0001\right)$. Common OTUs were defined as those that 520 fell within the upper quartile (dashed lines), and rare OTUs defined as those that did not. (b) Mean

521 OTU richness of whole, common and rare microbiota within the reared restricted (RR), reared foraged

522 (RF) and wild (W) bee groups. Asterisks denote significant differences in comparisons of diversity at 523 the $P<0.05$ level determined by two-sample $t$-tests $(t$-test summary statistics are given in Table S1).

524 (c) Taxa turnover within whole (solid squares), common (solid circles) and rare (open circles)

525 microbiota between sample groups. (d) Dendrogram of similarity between groups partitioned into the 526 whole (W), common (C) and rare (R) microbiota. Metacommunity profiles were compared using the

527 Bray-Curtis quantitative index of similarity and unweighted pair-group method using arithmetic mean 528 (UPGMA).

529

530 Figure 2 Unique and shared OTUs between groups. Values given within circles represent, unique 531 OTUs to the reared restricted (RR) group, reared foraged (RF), and wild (W) groups. Values given in 532 overlapping regions correspond to the number of OTUs shared between two given groups. Central 533 overlapping region corresponds to OTUs shared across all group types inclusive of the 28 common 534 OTUs. The arrow represents direction of proposed community transition from commercially reared to 535 wild type microbiota.

536 
Figure 1
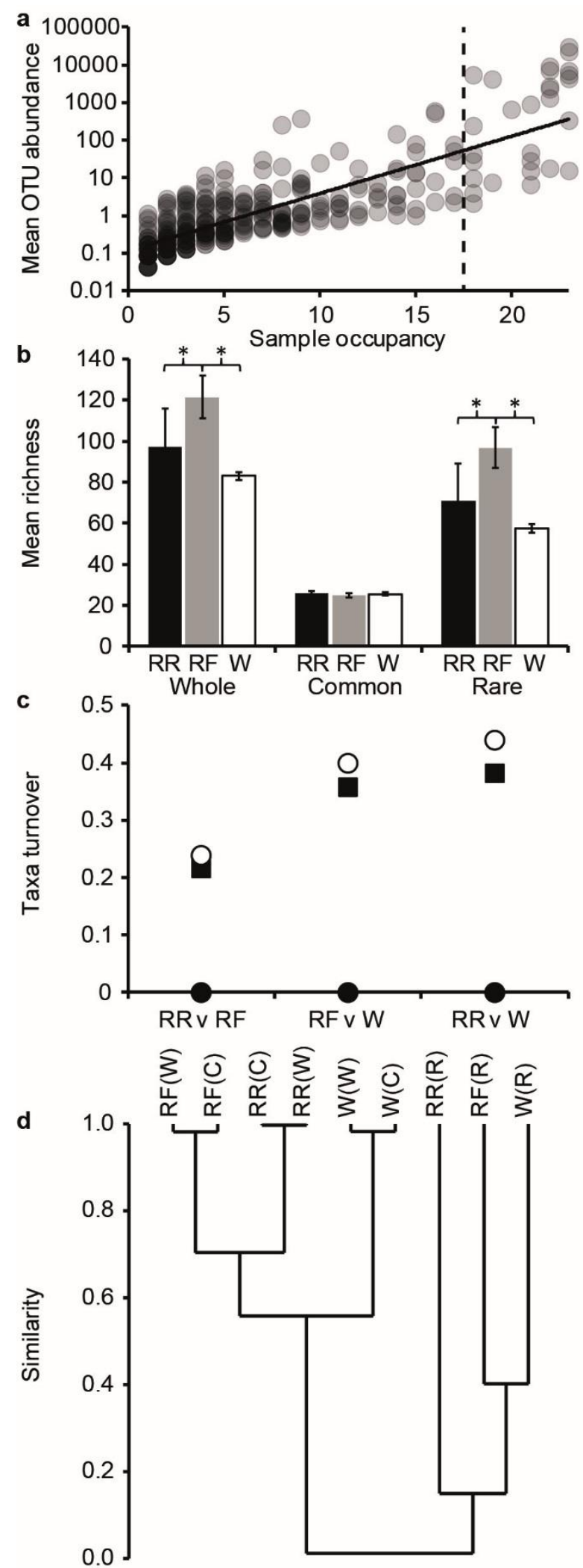
$542 \quad$ Figure 2

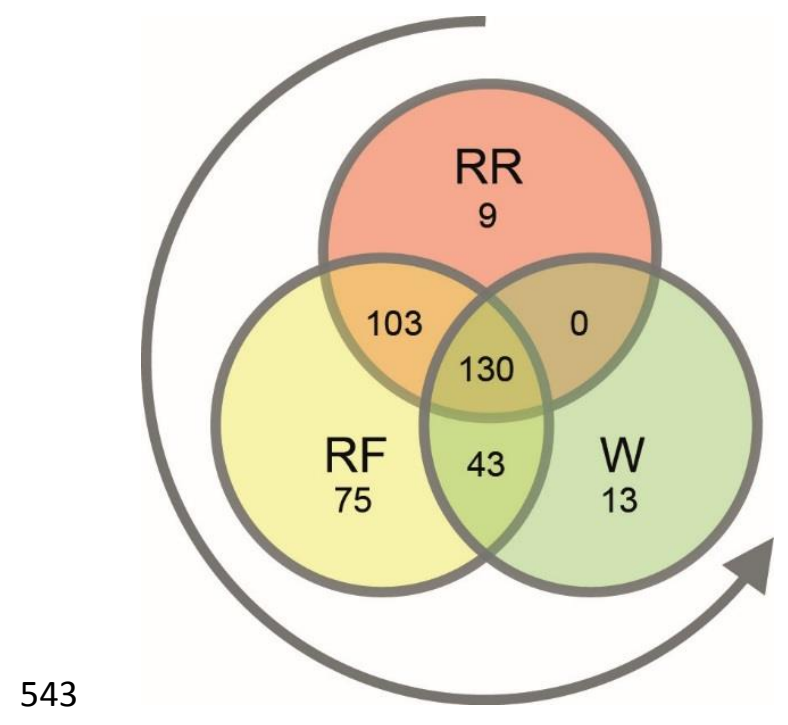


544 Table 1 Analysis of similarity (ANOSIM) of whole, common, and rare microbiota between reared

545 restricted (RR), reared foraged (RF), and wild (W) bee groups. ANOSIM test statistic $(R)$ and

546 probability $(P)$ that two compared groups are significantly different at the $P<0.05$ level (denoted with

547 asterisks) are given in the lower and upper triangles, respectively. ANOSIM $R$ and $P$ values were

548 generated using the Bray-Curtis measure of similarity.

549

550

\begin{tabular}{c|ccc}
\hline Whole & RR & RF & W \\
\hline RR & - & 0.990 & $0.008^{*}$ \\
RF & -0.177 & - & 0.832 \\
W & 0.295 & -0.085 & - \\
\hline Common & RR & RF & W \\
\hline RR & - & 0.992 & $0.009^{*}$ \\
RF & -0.177 & - & 0.869 \\
W & 0.298 & -0.092 & - \\
\hline Rare & RR & RF & W \\
\hline RR & - & 0.107 & $0.01^{*}$ \\
RF & 0.219 & - & 0.266 \\
W & 0.664 & 0.129 & - \\
\hline
\end{tabular}

551

552

553 


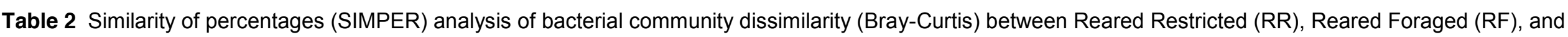
Wild (W) sample group whole microbiota. Given is mean \% abundance of sequences for operational taxonomic units across the samples each was observed to occupy and the average dissimilarity between samples ( RR vs. RF) $=58 \%$ and (RR vs. W) $=59 \%,(R F$ vs. W) $=67 \%)$. Percentage contribution is the mean

\begin{tabular}{|c|c|c|c|c|c|c|c|c|}
\hline \multirow[b]{2}{*}{ Class } & \multirow[b]{2}{*}{ Family } & \multirow[b]{2}{*}{ Taxon name } & \multicolumn{3}{|c|}{$\%$ Mean abundance } & \multirow[b]{2}{*}{ Av. dis. } & \multirow[b]{2}{*}{ Cont\% } & \multirow[b]{2}{*}{ Cuml. \% } \\
\hline & & & $\mathrm{RR}$ & RF & W & & & \\
\hline $\begin{array}{l}\text { Betaproteobacteria } \\
\text { Gammaproteobacteri }\end{array}$ & Neisseriaceae & Snodgrassella alvi 99\% & 52.1 & 29.5 & 22.4 & 16.16 & 26.19 & 26.19 \\
\hline $\begin{array}{l}\text { a } \\
\text { Gammaproteobacteri }\end{array}$ & Orbaceae & Gilliamella apicola 99\% & 22.3 & 17.9 & 30.9 & 9.50 & 15.38 & 41.57 \\
\hline a & Enterobacteriaceae & Arsenophonus nasoniae $99 \%$ & 0.02 & 6.06 & 15.8 & 6.84 & 11.08 & 52.65 \\
\hline Flavobacteriia & Flavobacteriaceae & Flavobacterium $83 \%$ & 0.00 & 9.31 & 7.76 & 5.39 & 8.74 & 61.39 \\
\hline Bacilli & Lactobacillaceae & Lactobacillus $91 \%$ & 6.72 & 7.70 & 1.84 & 4.31 & 6.98 & 68.37 \\
\hline $\begin{array}{l}\text { Bacilli } \\
\text { Gammaproteobacteri }\end{array}$ & Leuconostocaceae & Fructobacillus $100 \%$ & 0.02 & 0.29 & 12.5 & 4.18 & 6.78 & 75.15 \\
\hline a & Enterobacteriaceae & Yokenella 98\% & 7.44 & 6.04 & 0.25 & 4.03 & 6.52 & 81.67 \\
\hline Bacilli & Lactobacillaceae & Lactobacillus kunkeei 100\% & 0.17 & 4.63 & 3.78 & 2.86 & 4.63 & 86.31 \\
\hline $\begin{array}{l}\text { Bacilli } \\
\text { Gammaproteobacteri }\end{array}$ & Enterococcaceae & Vagococcus $100 \%$ & 4.47 & 3.66 & 0.05 & 2.50 & 4.04 & 90.35 \\
\hline $\begin{array}{l}\text { a } \\
\text { Gammaproteobacteri }\end{array}$ & Streptococcaceae & Lactococcus $98 \%$ & 0.12 & 4.92 & 0.06 & 1.92 & 3.11 & 93.46 \\
\hline a & Pseudomonadaceae & Pseudomonas $100 \%$ & 2.66 & 2.27 & 0.01 & 1.53 & 2.48 & 95.93 \\
\hline Actinobacteria & Bifidobacteriaceae & Bombiscardovia coagulans $98 \%$ & 1.06 & 1.73 & 0.87 & 0.94 & 1.52 & 97.46 \\
\hline Bacilli & Enterococcaceae & Enterococcus $100 \%$ & 0.98 & 1.29 & 0.04 & 0.68 & 1.11 & 98.56 \\
\hline
\end{tabular}


561 Table 3 Canonical correspondence analyses (CCA) for determination of percent variation in the whole, common, and rare microbiota between the three subject groups by environmental variables significant at the $P<0.05$ level. CCA biplots are given in Figure S1.

564

\begin{tabular}{lllllll}
\hline & Whole & \multicolumn{3}{c}{ Common } & \multicolumn{2}{l}{ Rare } \\
\cline { 2 - 7 } & $\%$ variance & $P$ & $\%$ variance & $P$ & $\%$ variance & $P$ \\
\hline Foraging & 8.44 & 0.001 & 8.45 & 0.001 & 6.55 & 0.001 \\
Rearing & 7.93 & 0.002 & 7.93 & 0.001 & 10.74 & 0.001 \\
Host weight & 3.10 & 0.002 & 2.76 & 0.001 & 10.25 & 0.001 \\
Undetermined & 80.53 & - & 80.86 & - & 72.46 & - \\
\hline
\end{tabular}

565

566 

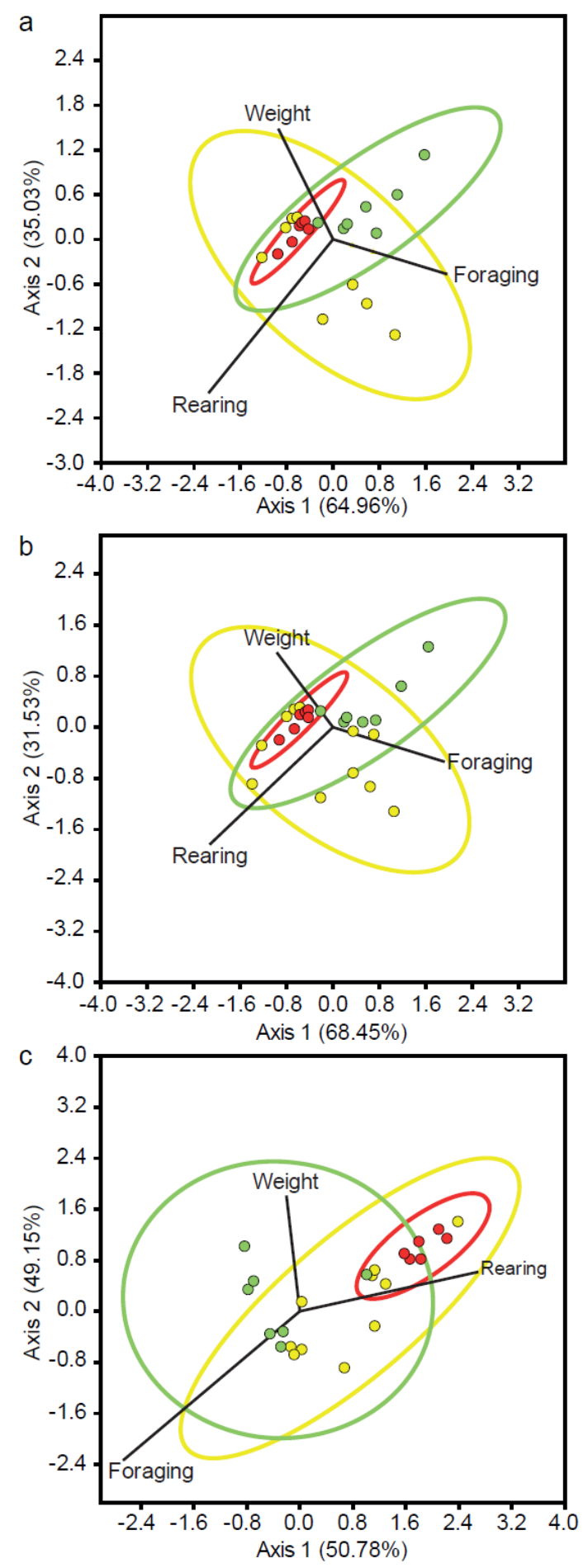

Figure $\mathbf{S 1}$ Canonical correspondence bi-plots for (a) whole, (b) common, and (c) rare microbiota. Solid red circles represent microbiota samples from the reared restricted (RR) group, solid yellow circles for the reared foraged (RF) group, and solid green circles for the wild (W) group. In each instance, the $95 \%$ concentration ellipses are given for the RR (red), RF (yellow), and W (green) group microbiota. Bi-plot lines for variables that significantly accounted for variation within the microbiota at the $P<0.05$ level (see Table 3) show the direction of increase for each variable, and the length of each line indicates the degree of correlation with the ordination axes. CCA field labels: rearing, foraging, and host weight. Percentage of community variation explained by each axis is given in parentheses. 
576

8
Table S1 Two-sample $t$-tests comparing mean whole, common, and rare microbiota richness between reared restricted (RR), reared foraged (RF), and wild (W) bee cohorts. Two-sample $t$-test statistic $(t)$ and significance $(P)$ that richness between two compared groups is significantly different at the $P<0.05$ level (denoted with asterisks) are given in the lower and upper triangles, respectively.

\begin{tabular}{c|ccc}
\hline Whole & RR & RF & W \\
\hline RR & - & $0.027^{*}$ & 0.125 \\
RF & 2.91 & - & $0.0001^{*}$ \\
W & 1.85 & 11.45 & - \\
\hline Common & RR & RF & W \\
\hline RR & - & 0.054 & 0.499 \\
RF & 2.18 & - & 0.07 \\
W & 0.71 & 1.96 & - \\
\hline Rare & RR & RF & W \\
\hline RR & - & $0.019^{*}$ & 0.122 \\
RF & 3.2 & - & $0.0001^{*}$ \\
W & 1.86 & 12.33 & - \\
\hline
\end{tabular}


579 Table S2 Sample details and barcodes used with their associated samples are given below.

\begin{tabular}{|c|c|c|c|c|c|c|}
\hline $\begin{array}{l}\text { Sampl } \\
\text { e }\end{array}$ & Origin & $\begin{array}{c}\text { Foraged }(\mathrm{F}) \\
\text { or } \\
\text { Restricted } \\
(\mathrm{R}) \\
\end{array}$ & Geography & $\begin{array}{l}\text { Total wet weight } \\
(\mathrm{g})\end{array}$ & $\begin{array}{l}\text { Gut wet weight } \\
\text { (g) }\end{array}$ & Barcode Sequence \\
\hline RR1 & $\begin{array}{l}\text { Commercially } \\
\text { reared } \\
\text { Commercially }\end{array}$ & $\mathrm{R}$ & $\mathrm{n} / \mathrm{a}$ & 0.175 & 0.01 & GATCTGCGATCC \\
\hline RR2 & $\begin{array}{l}\text { reared } \\
\text { Commercially }\end{array}$ & $\mathrm{R}$ & $\mathrm{n} / \mathrm{a}$ & 0.194 & 0.017 & AGTCGTGCACAT \\
\hline RR3 & $\begin{array}{l}\text { reared } \\
\text { Commercially }\end{array}$ & $\mathrm{R}$ & $\mathrm{n} / \mathrm{a}$ & 0.166 & 0.012 & CGAGGGAAAGTC \\
\hline RR4 & $\begin{array}{l}\text { reared } \\
\text { Commercially }\end{array}$ & $\mathrm{R}$ & $\mathrm{n} / \mathrm{a}$ & 0.233 & 0.06 & CAAATTCGGGAT \\
\hline RR5 & $\begin{array}{l}\text { reared } \\
\text { Commercially }\end{array}$ & $\mathrm{R}$ & $\mathrm{n} / \mathrm{a}$ & 0.207 & 0.017 & $\begin{array}{l}\text { AGATTGACCAAC } \\
\text { AGTTTACGAGCT }\end{array}$ \\
\hline RR6 & $\begin{array}{l}\text { reared } \\
\text { Commercially }\end{array}$ & $\mathrm{R}$ & $\mathrm{n} / \mathrm{a}$ & 0.1512 & 0.016 & A \\
\hline RF1 & $\begin{array}{l}\text { reared } \\
\text { Commercially }\end{array}$ & $\mathrm{F}$ & Wallingford & 0.251 & 0.04 & CAGCTCATCAGC \\
\hline RF2 & $\begin{array}{l}\text { reared } \\
\text { Commercially }\end{array}$ & $\mathrm{F}$ & Wallingford & 0.308 & 0.036 & CAAACAACAGCT \\
\hline RF3 & $\begin{array}{l}\text { reared } \\
\text { Commercially }\end{array}$ & $\mathrm{F}$ & Wallingford & 0.277 & 0.042 & GCAACACCATCC \\
\hline RF4 & $\begin{array}{l}\text { reared } \\
\text { Commercially }\end{array}$ & $\mathrm{F}$ & Wallingford & 0.176 & 0.034 & GCGATATATCGC \\
\hline RF5 & $\begin{array}{l}\text { reared } \\
\text { Commercially }\end{array}$ & $\mathrm{F}$ & Wallingford & 0.192 & 0.032 & GTATCTGCGCGT \\
\hline RF6 & $\begin{array}{l}\text { reared } \\
\text { Commercially }\end{array}$ & $\mathrm{F}$ & Wallingford & 0.15 & 0.034 & GCATATGCACTG \\
\hline RF7 & $\begin{array}{l}\text { reared } \\
\text { Commercially }\end{array}$ & $\mathrm{F}$ & Wallingford & 0.148 & 0.028 & CAACTCCCGTGA \\
\hline RF8 & $\begin{array}{l}\text { reared } \\
\text { Commercially }\end{array}$ & $\mathrm{F}$ & Wallingford & 0.172 & 0.01 & TTGCGTTAGCAG \\
\hline RF9 & $\begin{array}{l}\text { reared } \\
\text { Commercially }\end{array}$ & $F$ & Wallingford & 0.143 & 0.014 & TACGAGCCCTAA \\
\hline RF10 & reared & $\mathrm{F}$ & Wallingford & 0.286 & 0.025 & ATCACCAGGTGT \\
\hline W1 & Wild & $\mathrm{F}$ & Hillesden & 0.187 & 0.017 & CGAGCAATCCTA \\
\hline W2 & Wild & $\mathrm{F}$ & Hillesden & 0.196 & 0.011 & TAATACGGATCG \\
\hline W3 & Wild & $\mathrm{F}$ & $\begin{array}{l}\text { Hillesden } \\
\text { Isle of }\end{array}$ & 0.261 & 0.029 & CATTCGTGGCGT \\
\hline W4 & Wild & $\mathrm{F}$ & $\begin{array}{l}\text { Wight } \\
\text { Isle of }\end{array}$ & 0.339 & 0.03 & TCCСTTGTCTCC \\
\hline W5 & Wild & $F$ & $\begin{array}{l}\text { Wight } \\
\text { Isle of }\end{array}$ & 0.162 & 0.026 & ACGAGACTGATT \\
\hline W6 & Wild & $\mathrm{F}$ & Wight & 0.22 & 0.022 & GCTGTACGGATT \\
\hline W7 & Wild & $\mathrm{F}$ & Hillesden & 0.279 & 0.03 & TGTGAATTCGGA \\
\hline
\end{tabular}

